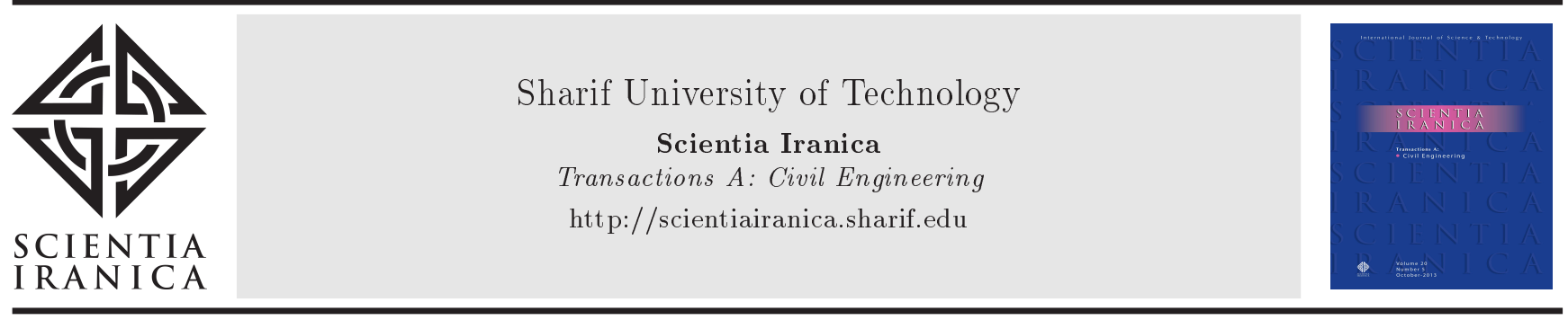

\title{
Optimum design of castellated beams: Effects of composite action and semi-rigid connections
}

\author{
A. Kaveh ${ }^{a, *}$ and M.H. Ghafari ${ }^{b}$ \\ a. Centre of Excellence for Fundamental Studies in Structural Engineering, Iran University of Science and Technology, Narmak, \\ Tehran, P.O. Box 16846-13114, Iran. \\ b. School of Civil Engineering, Iran University of Science and Technology, Narmak, Tehran, P.O. Box 16846-13114, Iran.
}

Received 15 May 2016; received in revised form 4 October 2016; accepted 10 December 2016

\author{
KEYWORDS \\ Structural \\ optimization; \\ Semi-rigid \\ connections; \\ End filled castellated \\ beams; \\ Composite beams; \\ Colliding Bodies \\ Optimization (CBO); \\ Enhanced Colliding \\ Bodies Optimization \\ (ECBO); \\ Particle Swarm \\ Optimization (PSO).
}

\begin{abstract}
Castellated beams and composite action of beams are widely applicable methods to increase the capacity of the beams. Semi-rigid connections can also redistribute internal moments in order to attain a better distribution. Combination of these methods helps to optimize the cost of the beam. In this study, some meta-heuristic algorithms consisting of the particle swarm optimization, colliding bodies optimization, and enhanced colliding bodies optimization are used for optimization of semi-rigid jointed composite castellated beams. Profile section, cutting depth, cutting angle, holes spacing, number of filled end holes of the castellated beams, and rigidity of connection are considered as the optimization variables. Constraints include the construction, moment, shear, deflection, and vibration limitations. Effects of partial fixity and commercial cutting shape of a castellated beam for a practical range of beam spans and loading types are studied through three numerical examples. The efficiency of three meta-heuristic algorithms is compared.
\end{abstract}

(C) 2018 Sharif University of Technology. All rights reserved.

\section{Introduction}

Optimizing the structural elements to achieve the best economical and serviceable result is one of the most desirable aims of the structural designers. A typical example of such a trend is the efforts of researchers to efficiently increase the capacity of beams. Castellated beams and composite beams can increase beams moment of inertia and this effect increases the bending moment capacity of the beams. However, both of them have some limitations and produce secondary effects

\footnotetext{
*. Corresponding author. Tel.: +98 2144202710 ;

Fax: +9821 rr7240398

E-mail address: alikaveh@iust.ac.ir (A. Kaveh)
}

that limit their usage. For example, in order to face the secondary shear effect of the castellated beams, some end hole should be filled.

One of the first studies that evaluated the effect of web opening on composite beams was performed by Redwood and Cho [1]. They also surveyed the failure modes of the hexagonal composite castellated beams. Several tests were performed by Jackson [2] showing that the AISC design guide procedures for composite prismatic beams could be used for calculating the natural frequency of the beams.

The effect of edge constraint component on flexural strength of composite beam was studied by Wang and Li [3]. Ellakani and Tablia [4] developed a numerical model for static and free vibration analysis of elastic composite beams with end shear restraint. They found that the end shear restraint played an 
important role when the composite beam interaction was not complete.

There have been several efforts for cost optimization of composite beam. Morton and Webber [5] optimized the composite I beams. They found that the fixed-end conditions led to lighter beams. Senouci and Al-Ansari [6] used the genetic algorithm for optimizations.

Optimization of castellated beams with several variables has been performed by many researchers. Sorkhabi et al. [7] optimized the castellated beams by PSO and Genetic Algorithm (GA) and found that PSO was better than GA. Kaveh and Shokohi $[8,9]$ optimized castellated beam with hexagonal and cellular opening by CBO and Charged System Search (CSS) meta-heuristic algorithms. They also considered the effect of end filled plates [10].

Semi-rigid composite connections have been modeled and tested by some researchers in recent years. Modeling of beam to girder semi-rigid composite connection with angles, including the effects of concrete tension stiffness, was studied by Oliveira and Batista [11]. They calibrated a modified theoretical model based on the component method and found a good agreement between the experimental and theoretical results. They observed the role of the concrete before and after crack development and stabilization and the shear lag effect in the slab. Fu et al. [12] modeled a 3D finite element model of semi-rigid composite end-plated connections. They presented the effects of longitudinal bar, thickness of the endplate, thickness of beam flange, etc. on capacity of the connection. Gil et al. [13] validated the design procedures experimentally and numerically. They found that the load level in the minor column axis had no influence on the behavior of the major one. Rex and Easterling [14] developed a simple method of approximating the moment-rotation behavior of composite beam-girder connection. They presented the effect of pre-loading on the moment rotation behavior.

Redistribution of internal member forces by semirigid connections can help designers to decrease the total cost of the building. Simoes [15] was one of the first researchers who optimized frame elements by semi-rigid connections. He used segmental method utilizing linear programming to solve optimization problems. Kameshki and Saka [16] utilized GA to optimize non-linear steel frame with semi-rigid connections. They considered $P-\Delta$ effect in their analysis. Ramires et al. [17] optimized the composite and steel endplate semi-rigid joints by GA. They found that the joint cost could be decreased by $10 \%$ by tuning the stiffness of the connections. Ali et al. [18] used the multi-stage design optimization by GA for semi-rigid steel frames, and their results showed that the cost of joints might constitute more than
$20 \%$ of the total cost of an optimized steel frame structure.

The main objective of the present paper is to study the composite action, semi rigidity of joint, and end holes filling on optimization of the castellated beams. The optimization algorithms used in this paper consist of the colliding body optimization, enhanced colliding body optimization, and particle swarm optimization. Optimization variables are profile section, cutting depth $\left(d_{h}\right)$, cutting angle $(\alpha)$, holes spacing $(s)$, number of filled end holes of the castellated beam, and rigidity of the connections $\left(R_{j}\right)$.

The present paper is organized as follows: In the next section, design of the castellated beams is introduced. In Section 3, design of the composite beams is provided. Semi-rigid connections are introduced briefly in Section 4. Some dependence features of semi rigidity, composite action, and castellated beams are discussed in Section 5. Three optimization algorithms that are used in this study are briefly introduced in Section 6 . Based on these sections, problem definition is presented in Section 7. In Section 8, some examples are optimized using different metaheuristics, and finally Section 9 concludes the paper.

\section{Design of castellated beams}

Increasing beam depth without using additional material by cuttings and welding beams is known as the castellated beam. This method produces a beam web and shape of the holes may be different depending on the cutting procedures. Hexagon and circle are two well-known and common shapes of the cutting. To avoid the stress concentration at angles of hexagonal shape, sinusoid cutting can be performed instead of hexagonal openings. Also, for both shapes of holes, secondary plates can be placed between two parts of the beam and increased depth of the beam. In the present study, simple hexagonal shape of castellated beam is considered, because this results in better design in optimization [8-10].

Determining the strength of the castellated beams is more complex than that of the standard beams. Interaction between shear and moment, horizontal shear and radial moment are the main differences between typical beam design process and castellated beam design procedure.

Unbraced length of the beams plays an important role in their flexural capacity. By considering the concrete on the top of the beam, unbraced length can be considered as zero and lateral-torsional buckling can be assumed not to occur.

In the following, the design procedure of the castellated beams is provided based on Load and Resistance Factor Design (LRFD) method of the AISC 360-10 [19]. 


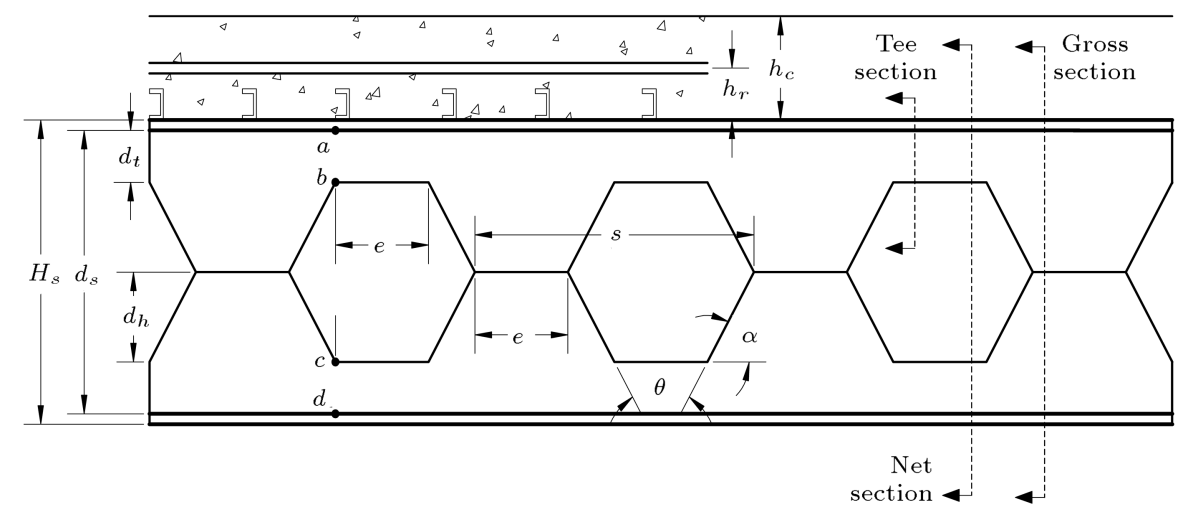

Figure 1. Details of a composite castellated beam.

\subsection{Flexural capacity}

Section plastic modulus of a beam identifies the moment capacity of the beam and the maximum moment under applied load should satisfy the following condition in AISC 360-10 [19]:

$$
M_{u}<\phi_{b} M_{n}=\phi_{b} F_{y} Z_{\text {net - st }},
$$

where $M_{u}$ is the ultimate moment of beam; $M_{n}$ is the nominal moment capacity of the beam; $Z_{n-s t}$ is the plastic module of steel net section; $\phi_{b}$ is the bending reduction factor; and $F_{y}$ is the yield strength of steel.

This equation is related to the general beam section. At the holes, Vierendeel mechanism identifies the flexural demand of the beam. In Vierendeel mechanism, two virtual hinges at top and bottom tee beams between two holes are considered. Vertical shear forces of these two tee beams produce secondary moment that is added to essential moment. Because of linear distribution of moment at depth of the beam, at points "a" and "c" depicted in Figure 1, sum of the two moments may be critical. Therefore, flexural capacity of the tee beam should satisfy the following equation in AISC 360-10 [19]:

$$
\begin{aligned}
& m_{u}=\frac{V_{u} \times e}{4}, \\
& \frac{M_{u}}{Z_{\text {net - st }}}+\frac{m_{u}}{Z_{\text {tee }}}<\phi_{b} F_{y},
\end{aligned}
$$

where $m_{u}$ is the ultimate moment of the secondary shear; $V_{u}$ is the ultimate shear force; $e$ is the web post length; $M_{u}$ is the ultimate moment; $Z_{\text {net-st }}$ is the plastic module of steel net section; and $Z_{\text {tee }}$ is the plastic module of steel tee section. $\phi_{b}$ for concrete and steel is considered to be equal to 0.9 .

By filling the hole, Vierendeel mechanism can be neglected.

\subsection{Shear capacity}

Three types of shear forces must be controlled in castellated beam.

First, overall shear capacity of the general section must satisfy the following equations in AISC 36010 [19]:

$$
\begin{aligned}
& A_{W}=d_{s} \times t_{w}, \\
& V_{u}<\phi_{v} V_{n-w}=\phi_{v} \times 0.6 F_{y} A_{W} C_{v},
\end{aligned}
$$

where $A_{w}$ is the area of the net section web; $t_{w}$ is the thickness of the web; $d_{s}$ is height of the internal castellated beam; $V_{u}$ is the ultimate shear force; $V_{n-w}$ is the nominal web shear capacity of net section; $\phi_{v}$ is the shear reduction factor; and $C_{v}$ is the web shear coefficient.

Second, vertical shear capacity of the tee beams must satisfy the following equations:

$$
\begin{aligned}
& A_{\text {tee }}=d_{t} \times t_{w}, \\
& \frac{V_{u}}{2}<\phi_{v} V_{n-\text { tee }}=\phi_{v} \times 0.6 F_{y} A_{\text {tee }} C_{v},
\end{aligned}
$$

where $A_{\text {tee }}$ is the area of each tee section and $V_{n-\text { tee }}$ is the nominal web shear capacity of tee section.

Third, horizontal shear capacity of post web must satisfy the following equations:

$$
\begin{aligned}
& A_{h e}=e \times t_{w}, \\
& V_{h}=\frac{V_{u} \times Q_{g}}{I_{g}} \times s<\phi_{v} V_{n-p}=\phi_{v} \times 0.6 F_{y} A_{h e} C_{v},
\end{aligned}
$$

where $V_{h}$ is the horizontal shear at post web; $Q_{g}$ and $I_{g}$ are the first and second moments of inertia of general section, respectively; $s$ is the spacing between the holes (Figure 1$) ; V_{n-p}$ is the nominal shear capacity of post web; $A_{h e}$ is web post horizontal shear area; and $\phi_{v}$ and $C_{v}$ are equal to 1 .

Because of the penetration of web welding, welding capacity is not critical at horizontal shear check. By filling the hole, horizontal shear can be controlled.

\subsection{Web post buckling}

Due to the horizontal shear, which was discussed above, web post plate performs similar to a cantilevered beam 
without flange, and at one side of it, compression forces produce instability by out of plane buckling [20]. The radial moment and capacity of the web post, according to Structural Stability Research Council (SSRC), must satisfy the following equations:

$$
\begin{aligned}
& C_{b}=1.75+1.05 \frac{M_{1}}{M_{2}}+0.3\left(\frac{M_{1}}{M_{2}}\right)^{2}<2.3, \\
& r_{T}=\frac{t_{w}}{\sqrt{12}}, \\
& C_{c}=\frac{2 \pi^{2} E}{F_{y}}, \\
& L_{b}=2 d_{h}, \\
& f_{r b}=\frac{3}{4} \frac{V_{h} \tan \theta}{t_{w} \theta^{2} e}<\phi_{b} F_{r b}=\left[1-\frac{\left(\frac{L_{b}}{r_{T}}\right)^{2}}{2 C_{c}^{2} C_{b}}\right] \phi_{b} F_{y},
\end{aligned}
$$

where $\theta, e$, and $d_{h}$ are the cutting angle, hole pure distance, and cutting depth of castellated beam (Figure 1$)$, respectively; $t_{w}$ is the thickness of the web; $M_{1}$ and $M_{2}$ are the moment at each beam end; $E_{s}$ is steel module of elasticity; and $\phi_{b}$ is equal to 0.9 , similar to the moment equation. trolled.

By filling the hole, radial moment can be con-

\section{Design of composite beams}

In composite beam with complete interaction, the center line should be found and then moment of inertia of the composite section should be calculated. In this study, temporary shores are considered for use during construction and only composite section is designed for the total live and dead loads. Effective width of the concrete slab should not exceed the limits as described in AISC 360-10 [19]:

1. One-eighth of the beam span, center-to-center of the connections;

2. One-half of the distance to the centerline of the adjacent beam;

3. The distance to the edge of the slab.

According to the height to web thickness ratio, $M_{n}$ should be determined from the superposition of elastic stresses or from the plastic stress distribution on the composite section. In this study, superposition of elastic stresses is considered because behavior of the composite castellated beam plastic is unpredictable.

In order to consider the effect of differential shrinkage and creep on a composite steel-concrete structure, effective length can be divided by 3 [21].
Shear studs are designed for transforming shear forces between steel and concrete completely. Shear and strength of the steel channel anchors, without considering compression steel effect, are determined according to AISC $360-10$ as follows [19]:

$$
\begin{aligned}
Q_{u}= & \min \left(0.85 F_{c} b_{e} h_{c}, A_{s} F_{y}\right)<N_{c} \phi_{v} Q_{n}=N_{c} \times \phi_{v} \\
& \times 0.3\left(t_{s-f}+0.5 t_{s-w}\right) L_{a} \sqrt{F_{c} E_{c}}
\end{aligned}
$$

where $F_{c}$ and $E_{c}$ are compression strength and elasticity module of concrete, respectively; $b_{e}$ and $h_{c}$ are the effective width and height of concrete, respectively; $A_{s}$ is the steel section area; $t_{s-f}, t_{s-w}$, and $L_{a}$ are flange thickness, web thickness, and width of the channel shear studs, respectively. Considering linear shear diagram, $N_{c}$ is half of the total number of shear studs and $\phi_{v}$ is equal to 0.75 .

In positive moment area, compression stress in top of the concrete must be less than allowable compression stress of concrete and tensile stress in the bottom of steel must be less than the allowable tensile stress of steel:

$$
\begin{aligned}
M_{u} & <\min \left(M_{n-\mathrm{con}}, M_{n-\mathrm{st}}\right) \\
& =\min \left(\phi_{b} 0.7 F_{c} Z_{n-\mathrm{com}-\mathrm{top}}, \phi_{b} F_{y} Z_{n-\mathrm{com}-\mathrm{bot}}\right),
\end{aligned}
$$

where $M_{n-\text { con }}$ and $M_{n-s t}$ are the nominal moment capacities of composite beam according to concrete part and steel part of the beam, respectively; $Z_{n-\text { com-bot }}$ and $Z_{n \text {-com-top }}$ are section modules of bottom part and top part of the composite net section, respectively.

$\phi_{b}$ for concrete and steel is considered to be equal to 0.9 (AISC 360-10) [19].

In negative moment area, cracked concrete cannot sustain tensile stress and only steel section should be considered as presented in Eq. (1).

The available shear strength of the composite beams will be determined based upon the properties of the steel section alone as presented in Eq. (5), AISC 360-10 [19].

\section{Semi-rigid connection}

Considering partial fixity in connection and redistribution of internal member forces by semi-rigid connection can help designers to decrease the total cost of building, Figure 2. Modeling, analyzing, and testing of this type of connections have been the subject of many research efforts. Linear, bi-linear, and tri-linear moment-rotation models can be adopted to describe the connection behavior. The component method is applied to define and estimate the properties of the connection [22]. It is usual to consider the web angles subjected to plastic behavior under construction loads 


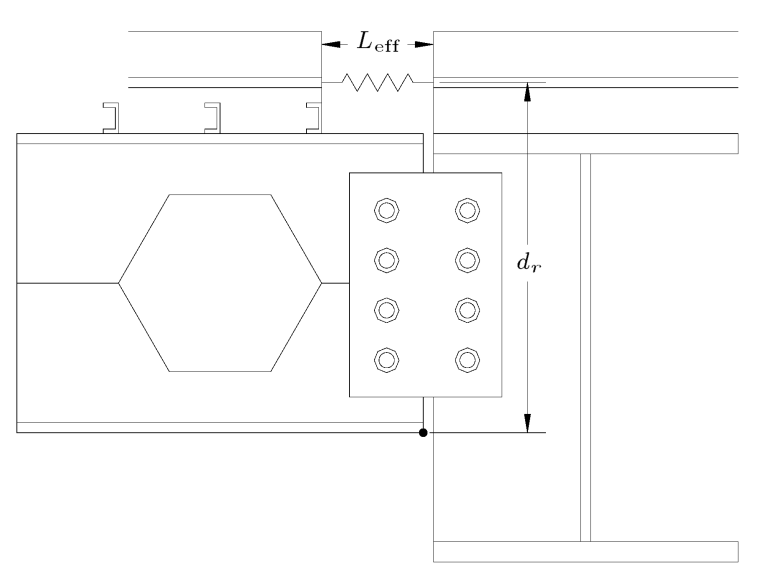

Figure 2. Model of a semi-rigid connection.

that do not contribute to the initial stiffness of the composite joint. Initial stiffness of joint $\left(S_{j, \text { ini }}\right)$ can be estimated by:

$$
\begin{aligned}
S_{j, \mathrm{ini}} & =\frac{\sum M_{i}}{d \psi}=\frac{\sum F_{i} \times d_{i}}{d \psi}=\frac{F_{s} \times d_{s}}{d \psi} \\
& =\frac{\frac{E_{s} A_{\mathrm{reb}}}{L_{\mathrm{eff}}} d_{r} d \psi \times d_{r}}{d \psi}=\frac{E_{s} A_{\mathrm{reb}}}{L_{\mathrm{eff}}}\left(d_{r}\right)^{2},
\end{aligned}
$$

where $M_{i}, F_{i}$, and $d_{i}$ are the moment, force, and distance, respectively, and $\psi$ is rotation of semi-rigid joint. $A_{\mathrm{reb}}, d_{r}$, and $L_{\mathrm{eff}}$ are the area, distance, and effective length of the rebars, respectively.

This equation is based on small rotation of connection and calculates the force and moment of the effective component.

In this study, the bilinear model presented in Murray et al. [23] is considered for semi-rigid connection, Figure 3. According to Silva et al. [22], the factor $\eta$ for beam to beam joint is considered 3 :

$$
S_{j}=\frac{S_{j, \text { ini }}}{\eta}
$$

where $S_{j}$ is the effective stiffness of semi-rigid connection.

After calculating $S_{j}$, from the basic equation for calculating rotation of the beam, the fixity factor, $R_{j}$,

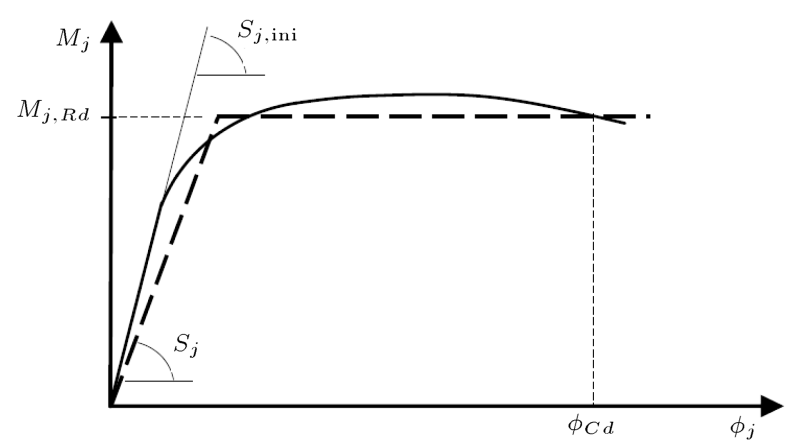

Figure 3. Bending moment-rotation curve of a joint [23]. for the distributed load is defined as:

$$
\begin{aligned}
R_{j} & =\frac{1}{1+\frac{2 E_{s} I_{\mathrm{def}}}{S_{j} L_{T}}}=\frac{1}{1+\frac{2 E_{s} I_{\mathrm{def}}}{\frac{E_{s} A_{\mathrm{reb}}}{L_{\mathrm{eff}}}\left(d_{s}\right)^{2} L_{T}} \times \eta} \\
& =\frac{1}{1+\frac{2 I_{\mathrm{def}} L_{\mathrm{eff}}}{A_{\mathrm{reb}}\left(d_{s}\right)^{2} L_{T}} \times \eta},
\end{aligned}
$$

where $I_{\text {def }}$ is the effective moment inertia for deflection calculation.

According to this equation, the properties of rebar can be determined. But, in the present study, only optimal fixity factor is calculated.

The common shrinkage and temperature reinforcements parallel to beam can help to have sufficient partial fixity. If there is no sufficient reinforcement, partial fixity will be limited.

Moment resistance of the semi-rigid joint must be controlled as:

$$
M_{u}<\phi_{b} M_{j-R d}=\phi_{b} F_{y-\mathrm{reb}} A_{\mathrm{reb}} d_{s}
$$

where $M_{j . R d}$ is the moment resistance of semi-rigid joint.

\section{Semi-rigid composite castellated beam}

\subsection{Deflection of semi-rigid composite castellated beam}

Simple equations govern the elastic flexural deflection of a typical beam. In the castellated beam, shear deformation should be considered. According to Jackson [2], real moment of inertia for deflection is close to the composite moment of inertia of net section. However, AISC design guide for floor vibration indicates that the shear studs are not sufficiently stiff to justify the fully transformed moment of inertia assumption for the composite beams; the following equation determines the effective moment of inertia [23]:

$$
I_{\mathrm{def}}=0.85 I_{n}+\frac{\left(I_{\mathrm{com}}-0.85 I_{n}\right)}{4}
$$

where $I_{\text {com }}$ and $I_{n}$ are the composite section and net section moments of inertia for deflection calculation. Also, the coefficient 0.85 identifies the shear effect for typical open web beam.

In negative moment area, three parts are important for calculating the deflection:

1. Deflection from changing end slope of the beam:

$$
\operatorname{def}_{1}=\tan \psi \times L_{\text {neg }} .
$$

2. Deflection of semi-cantilevered beam at negative moment part:

$$
\operatorname{def}_{2}=\frac{W L_{\mathrm{neg}}{ }^{4}}{8 E_{s} I_{n}}+\frac{\left(\frac{W L_{\mathrm{pos}}}{2}\right) L_{\mathrm{neg}}{ }^{3}}{3 E_{s} I_{n}} .
$$


3. Deflection of semi-pinned beam at positive moment part:

$$
\begin{aligned}
& \operatorname{def}_{3}=\frac{5 W L_{\mathrm{pos}}{ }^{4}}{384 E_{s} I_{\mathrm{def}}}, \\
& \operatorname{def}=\operatorname{def}_{1}+\operatorname{def}_{2}+\operatorname{def}_{3}<\operatorname{def}_{\text {all }}=\frac{L_{\mathrm{pos}}}{360},
\end{aligned}
$$

where $L_{\text {neg }}$ and $L_{\text {pos }}$ are the lengths of the negative and positive parts of the beam, respectively.

For concentrated loading, similar calculation must be performed.

\subsection{Vibration of semi-rigid composite castellated beam}

Frequency of the load carrying system of a floor is the most important factor to identify the level of serviceability of the floor. Frequency is related to the stiffness of the beam, boundary condition, and distribution of the mass.

The maximum initial amplitude of the beam is the other important parameter to identify the serviceability level of a floor.

Frequency of beam can be estimated by [24]:

$$
\begin{aligned}
& \operatorname{def}_{\mathrm{vib}}=\frac{\operatorname{def}_{1}+\operatorname{def}_{2}}{+} \operatorname{def}_{3} 1.5+\operatorname{def}_{\mathrm{col}},
\end{aligned}
$$

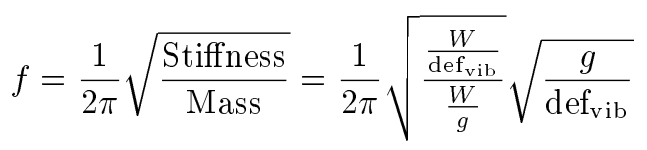

$$
\begin{aligned}
& =\frac{1}{2 \pi} \sqrt{\frac{g}{\operatorname{def}_{\mathrm{vib}}},}
\end{aligned}
$$

where $W$ and $g$ are the effective weight and gravity acceleration, respectively.

def $_{\text {col }}$ is considered zero and $W$ can be calculated by 0.2 time the live load in addition to dead loads.

The maximum initial amplitude (inch) of the beam is determined as [24]:

$$
\begin{aligned}
A_{o t}= & (\mathrm{DLF})_{\max } \\
& \times\left(\frac{0.6\left(L_{\mathrm{pos}} \times 0.393\right)^{3}}{48\left(E_{s} \times 14.22 \times 10^{-3}\right)\left(I_{\mathrm{def}} \times 0.393^{4}\right)}\right) \\
N_{\mathrm{eff}}= & 2.97-0.0578 \times\left(\frac{S_{b}}{h_{c}}\right)+2.56 \times 10^{-8} \\
& \times\left(\frac{L_{\mathrm{pos}}{ }^{4}}{I_{\mathrm{def}}}\right)+0.0001\left(\frac{L}{S_{b}}\right)^{3} \\
A_{0}= & \frac{A_{o t}}{N_{\mathrm{eff}}}
\end{aligned}
$$

where $S_{b}$ is beam spacing and $h_{c}$ is concrete height. $(\mathrm{DLF})_{\max }$ values for various natural frequencies are presented in [24].

The required damping ratio for the specified amplitude and frequency is determined by [24]:

$$
D_{\text {req }}=35 A_{o} f+2.5<D_{\text {all }}=0.035 \text {. }
$$

For a damping ratio above $3.5 \%$, designer must either identify an exact source of damping or artificially provide additional damping to be sure that the floor system is satisfactory [24].

\section{Optimization algorithms}

There are many methods for solving the optimization problems. Mathematical programming based methods solve these problems when the objective function and constraints have linear or non-linear relationship and gradients of the functions are easily accessible. Because of complexity of the structural optimization, many problems in this field cannot be easily handled by mathematical programming methods. After 1988, meta-heuristic based methods were gradually developed and increasing the power of the computers helped the researchers to solve optimization problems more efficiently. Genetic Algorithm (GA) [25] and Particle Swarm Optimization (PSO) [26] are the most common ones.

In this paper, the PSO, CBO, and ECBO algorithms are used. In order to have reasonable comparison, the number of iterations and the number of population sizes are selected to be the same in all three algorithms.

PSO is based on sharing information between each pair of particles in the swarm and updating each particle's position based on its memory and the data gained regarding other particles.

\section{1. $C B O$ and $E C B O$}

Colliding Bodies Optimization (CBO) is a recently developed meta-heuristic algorithm [27]. In this method, one object collides with another object and they move towards a minimum energy level. The CBO is simple in concept and depends on no internal parameter. Each Colliding Body $(\mathrm{CB})$ has a specified mass related to the fitness function. In order to select pairs of objects for collision, CBs are sorted according to their mass in a decreasing order and they are divided into two equal groups: stationary and moving. Moving objects collide with stationary objects to improve their positions and push stationary objects towards better positions.

In order to improve the $\mathrm{CBO}$ to get faster and more reliable solutions, Enhanced Colliding Bodies Optimization (ECBO) is developed by utilizing a memory to save a number of historically best CBs as well as by using a mechanism to escape from local optima [28]. 


\section{Problem definition}

\subsection{Cost function}

Total cost function is defined in the following form:

$$
\operatorname{Cost}_{\text {ini }}=\operatorname{Cost}_{p}+\operatorname{Cost}_{W}+\operatorname{Cost}_{c}+\operatorname{Cost}_{s} .
$$

Each sub-cost is determined by multiplying the corresponding weight (for Cost $p$ and Cost ${ }_{s}$ ) or length (Cost ${ }_{w}$ and Cost $_{c}$ ) by appropriate coefficient. Values of these coefficients are determined either by other researchers [9] or by engineering experiences:

$$
\begin{aligned}
& P_{p}=2 \times\left((s-2 e)+\left(H_{s}-2 d_{t}\right)\right), \\
& N_{h}=\left[\frac{L_{T}}{s}\right] \\
& L_{w}=\left(N_{h}+1-2 \times N_{f h}\right) \times e+P_{p} \times N_{f h} \times 4, \\
& \operatorname{Cost}_{w}=\left(L_{w}\right) \times C_{w}, \\
& \operatorname{Cost}_{p}=\left(A_{s} \times L_{T}\right) \times C_{p}, \\
& \operatorname{Cost}_{c}=\left(2 \times L_{w}+2 \times \frac{N_{h} \times d_{h}}{\operatorname{Sin}(\alpha)}+P_{p} \times N_{f h} \times 4\right) \times C_{c}, \\
& \operatorname{Cost}_{s}=\left(L_{a} \times A_{s s} \times N_{s s} \times \rho_{s}\right) \times C_{s},
\end{aligned}
$$

where $p, w, c$, and $s$ are profile, welding, cutting, and shear studs, respectively. $N_{s s}$ and $A_{s s}$ are the number and area of channel shear studs, respectively. $\alpha, s, e$, $H_{s}, d_{h}$, and $d_{t}$ are represented in Figure 1. $N_{h}$ and $N_{f h}$ are the total and filled hole numbers, respectively.

As described in pervious equations, the cost of filling end holes by plates is considered by adding their weights, cutting length, and welding length to the total cost. Cost coefficients are given in Table 1.

\subsection{Variables}

In this study, 6 variables are used for finding optimum results consisting of profile section, cutting depth $\left(d_{h}\right)$, cutting angle $(\alpha)$, holes spacing $(s)$, number of filled end holes of the castellated beams, and rigidity of the connection $\left(R_{j}\right)$. The minimum and maximum magnitudes of the variables must be clear for avoiding non-acceptable results and for fast convergence to the global optimum. Profile section is the sequence number

Table 1. Cost coefficients.

\begin{tabular}{ccc}
\hline Coefficient & Value & Unit \\
\hline$C_{p}$ & 0.3 & $\$$ per each $\mathrm{kg}$ \\
$C_{w}$ & 1 & $\$$ per each $\mathrm{m}$ \\
$C_{c}$ & 0.8 & $\$$ per each $\mathrm{m}$ \\
$C_{s}$ & 2.4 & $\$$ per each $\mathrm{kg}$ \\
\hline
\end{tabular}

of the rolled steel profile in the standard steel section list (British Standards) starting from $127 \times 76 \times 13$ UB and ending in $914 \times 419 \times 388 \mathrm{UB}$. Cutting angle is limited between $40^{\circ}$ to $64^{\circ}$. Other bounds for variables are presented in the constraints.

In a real structure, it is not common to have different cutting shapes for one beam. Commercial cutting shapes for castellated beams vary in different countries. The characteristic properties of one of the most popular commercial shapes are as follows:

1. Cutting angle is equal to $63.4^{\circ}$;

2. Cutting depth is half of the beam height;

3. Holes spacing is three times the cutting depth.

\subsection{Constraints}

As mentioned in the previous section, there are some design constraints as follows:

$$
\begin{aligned}
& g_{1}=d_{h}-\frac{3}{8}\left(H_{s}-2 t_{f}\right), \\
& g_{2}=\left(H_{s}-2 t_{f}\right)-10\left(d_{t}-t_{f}\right), \\
& g_{3}=\frac{2}{3} d_{h} \cot (\alpha)-e, \\
& g_{4}=e-2 d_{h} \cot (\alpha) \\
& g_{5}=2 d_{h} \cot (\alpha)+e-2 d_{h}, \\
& g_{6}=M_{u}-\phi_{b} M_{n-s t}, \\
& g_{7}=\frac{M_{u}}{Z_{n-\mathrm{com}-\mathrm{bot}}}+\frac{m_{u}}{Z_{\mathrm{tee}-\mathrm{com}}}-\phi_{b} F_{y}, \\
& g_{8}=M_{u}-\phi_{b} M_{n-\mathrm{con}}, \\
& g_{9}=M_{u}-M_{j-R d}, \\
& g_{10}=V_{u}-\phi_{v} V_{n-w} \\
& g_{11}=\frac{V_{u}}{2}-\phi_{v} V_{n-\text { tee }} \\
& g_{12}=V_{h}-\phi_{v} V_{n-p}, \\
& g_{13}=f_{r b}-\phi_{b} F_{r b}, \\
& g_{14}=\operatorname{def}-d e f_{\text {all }}, \\
& g_{15}=D_{\text {req }}-D_{\text {all }},
\end{aligned}
$$

$g_{1}$ to $g_{5}$ are related to constructional procedure of manufacturing the castellated beams [9]. Also, in order to have a good comparison between constraints, they are normalized. 


\subsection{Penalty function}

In order to avoid non-acceptable results, penalty function increases the cost of results that do not satisfy the constraints. The constraint is satisfied when $g_{i}$ is greater than zero. Thus, sum of the non-satisfying constraints can show the degree of non-acceptability. According to the above sentences, penalty factor is defined by the following equation:

$$
\begin{aligned}
& \mathrm{PF}=10^{N A C}, \\
& \mathrm{NAC}=\operatorname{sum}\left(g_{i}>0\right), \\
& \text { Cost }_{\text {fin }}=\text { Cost }_{\text {ini }} \times \mathrm{PF},
\end{aligned}
$$

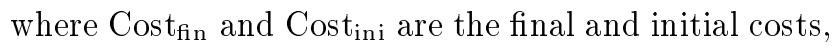
respectively.

Normalizing constraints also helps to have good results when they are summed together.

\section{Design examples}

In order to compare the fabrication cost of the semirigid joint composite castellated beams with those of different methods, three examples are selected. Modulus of elasticity is taken $205 \mathrm{kN} / \mathrm{mm}^{2}$ and grade 50 is selected for the steel of the beam, which has the design strength of $355 \mathrm{MPa}$. Concrete design strength is equal to $25 \mathrm{MPa}$. The combinations for live and dead loads are defined as those in ASCE [29].

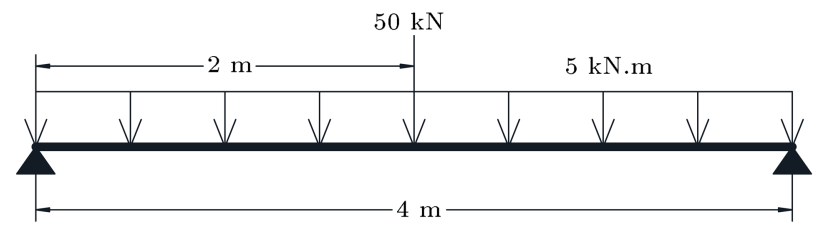

Figure 4. Schematics of the beam in Example 1.

\subsection{Example 1}

A simply supported beam with $4 \mathrm{~m}$ span, shown in Figure 4 , is selected as the first design example. The beam is subjected to $5 \mathrm{kN} / \mathrm{m}$ dead load, including its own weight, and concentrated live load of $50 \mathrm{kN}$. Effective width and height of concrete are $150 \mathrm{~cm}$ and $10 \mathrm{~cm}$, respectively. Number of iterations and population size are considered 80 and 100, respectively, for all the utilized algorithms.

\subsection{Example 2}

A simply supported beam with $9 \mathrm{~m}$ span, shown in Figure 5, is selected as the second design example. The beam is subjected to $40 \mathrm{kN} / \mathrm{m}$ dead load, including its own weight, and two concentrated live loads of $50 \mathrm{kN}$. Effective width and height of concrete are $150 \mathrm{~cm}$ and $15 \mathrm{~cm}$, respectively. For all the considered algorithms, the number of iterations and population size are considered 120 and 150, respectively.

Table 2 summarizes the main objectives of the

\begin{tabular}{|c|c|c|c|c|c|c|c|c|c|}
\hline $\begin{array}{c}\text { Combination } \\
\text { type }\end{array}$ & $\begin{array}{c}\text { Castellated } \\
\text { beam }\end{array}$ & $\begin{array}{c}\text { Composite } \\
\text { beam }\end{array}$ & $\begin{array}{l}\text { Semi-rigid } \\
\text { connection }\end{array}$ & $\begin{array}{c}\text { Filled hole } \\
\text { at end }\end{array}$ & $\begin{array}{c}\text { Cost } \\
(\$)\end{array}$ & $\%$ & $\begin{array}{c}\text { Critical } \\
\text { constraint }^{*}\end{array}$ & & \\
\hline \multicolumn{10}{|c|}{ Example 1} \\
\hline $\begin{array}{c}\text { Kaveh and } \\
\text { Shokohi [10] }\end{array}$ & $\sqrt{ }$ & - & - & $\sqrt{ }$ & 96.04 & 1.24 & & & \\
\hline 1 & $\sqrt{ }$ & - & - & $\sqrt{ }$ & 77.72 & 1.00 & HS & FM & \\
\hline 2 & $\sqrt{ }$ & - & $\sqrt{ }$ & - & 77.53 & 1.00 & HS & & \\
\hline 3 & $\sqrt{ }$ & $\sqrt{ }$ & - & - & 67.74 & 0.87 & DE & & \\
\hline 4 & $\sqrt{ }$ & - & $\sqrt{ }$ & $\sqrt{ }$ & 77.53 & 1.00 & HS & & \\
\hline 5 & $\sqrt{ }$ & $\sqrt{ }$ & - & $\sqrt{ }$ & 67.74 & 0.87 & DE & & \\
\hline 6 & $\sqrt{ }$ & $\sqrt{ }$ & $\sqrt{ }$ & - & 67.74 & 0.87 & DE & & \\
\hline 7 & $\sqrt{ }$ & $\sqrt{ }$ & $\sqrt{ }$ & $\sqrt{ }$ & 61.61 & 0.79 & FM & DE & \\
\hline \multicolumn{10}{|c|}{ Example 2} \\
\hline $\begin{array}{l}\text { Kaveh and } \\
\text { Shokohi [10] }\end{array}$ & $\sqrt{ }$ & - & - & $\sqrt{ }$ & 1031 & 1.59 & & & \\
\hline 1 & $\sqrt{ }$ & - & - & $\sqrt{ }$ & 647 & 1.00 & DE & RM & FM \\
\hline 2 & $\sqrt{ }$ & - & $\sqrt{ }$ & - & 613 & 0.95 & HS & RM & FM \\
\hline 3 & $\sqrt{ }$ & $\sqrt{ }$ & - & - & 605 & 0.94 & HS & $\mathbf{R M}$ & DE \\
\hline 4 & $\sqrt{ }$ & - & $\sqrt{ }$ & $\sqrt{ }$ & 489 & 0.76 & HS & RM & \\
\hline 5 & $\sqrt{ }$ & $\sqrt{ }$ & - & $\sqrt{ }$ & 605 & 0.94 & HS & RM & DE \\
\hline 6 & $\sqrt{ }$ & $\sqrt{ }$ & $\sqrt{ }$ & - & 605 & 0.94 & HS & RM & DE \\
\hline 7 & $\sqrt{ }$ & $\sqrt{ }$ & $\sqrt{ }$ & $\sqrt{ }$ & 431 & 0.67 & HS & RM & DE \\
\hline
\end{tabular}
performed optimizations. Four methods are presented

Table 2. Comparison of the optimum designs for the considered examples.

*HS: Horizontal Shear, DE: Deflection, FM: Flexural Moment, RM: Radial Moment. 


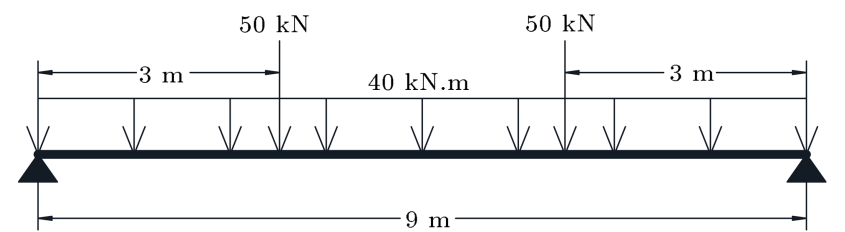

Figure 5. Schematics of the beam in Example 2.

at each column and their combinations are marked at each row by $\sqrt{ }$. Net cost and relative cost are displayed in two columns. Over $90 \%$ ratio constraint is called critical constraint and the ratio constraints are shown in the last columns.

The results of the examples are shown in Table 3. Figure 6 shows the variation of cost versus the number of iterations for Example 2.

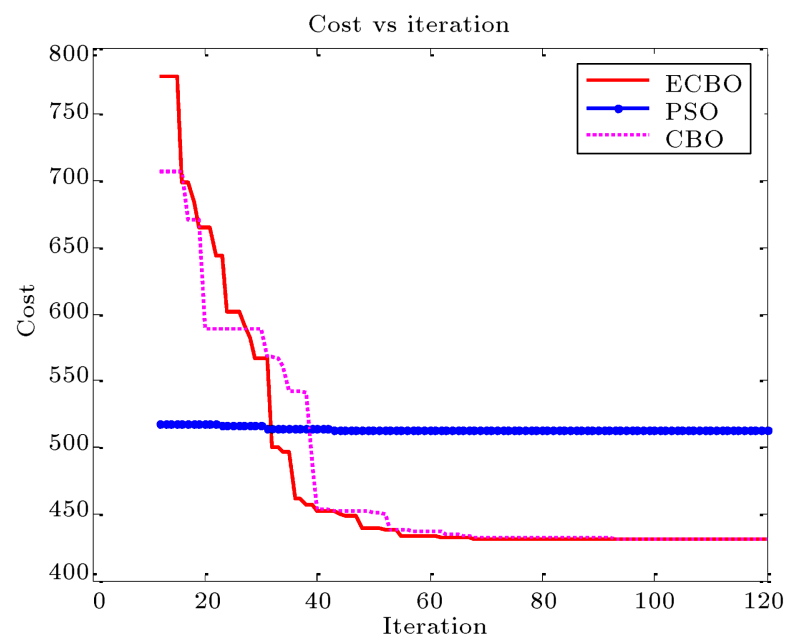

Figure 6. Variation of cost versus the number of iterations in Example 2.

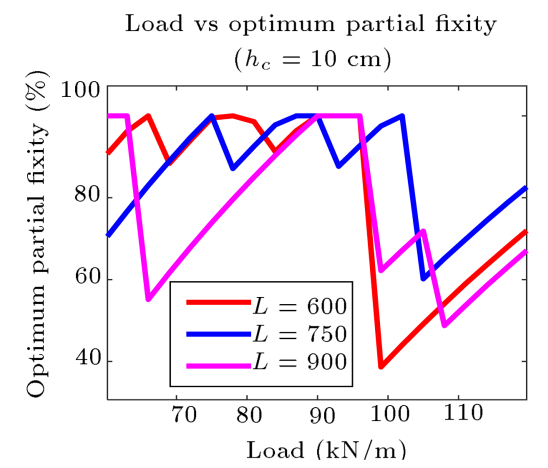

\subsection{Example 3}

In this example, a simply supported composite beam with different spans $(600,750$, and $900 \mathrm{~cm})$ is subjected to $50 \mathrm{kN} / \mathrm{m}$ to $100 \mathrm{kN} / \mathrm{m}$ dead load, including its own weight, having no concentrated load. Effective width of the concrete is $150 \mathrm{~cm}$ and concrete heights are $15 \mathrm{~cm}$ and $10 \mathrm{~cm}$. In order to study the effect of partial fixity and use of commercial cutting shape, the following conditions are considered.

\subsubsection{Optimum value of partial fixity}

For neglecting the effect of cutting shape and focusing on the partial fixity, a commercial shape of the castellated beams is considered. Also, two holes of each end are considered to be filled. Thus, only partial fixity and beam section are variables. Due to the reduction in the number of variables, the maximum number of iterations and population size are considered 30 and 20 , respectively. Here, only ECBO algorithm is used to find the optimum result.

Figure 7 shows that the optimum partial fixity can be changed from 40 to 100 percent, and there is no clear relationship among fixity and beam span, intensity of distributed load, and concrete thickness.

\subsubsection{Cost saving of the use of partial fixity connection}

Similar to the previous section, to ignore the effect of cutting shape and to focus on the effect of partial fixity, commercial shape of castellated beam is considered. Also, two holes of each end are considered to be filled. Hence, only partial fixity and beam section are variables. For each choice of span and load, two optimum results are found; one for the partial fixity condition and the other for simple connection

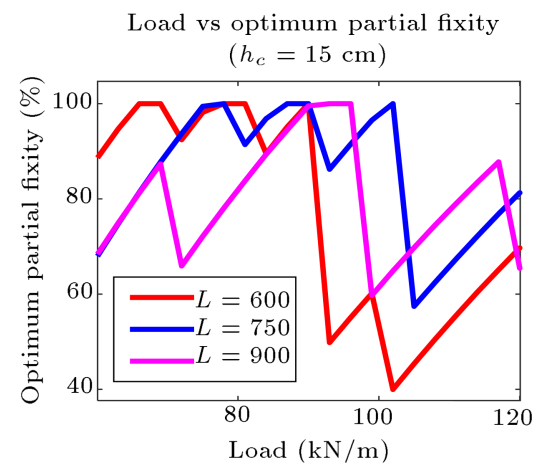

Figure 7. Optimum partial fixity percent versus the intensity of distributed load with $10 \mathrm{~cm}$ and $15 \mathrm{~cm}$ concrete thicknesses in Example 3.

Table 3. Results of the examples.

\begin{tabular}{lcccccccc}
\hline & \multirow{2}{*}{ Section } & $\begin{array}{c}\text { Cutting } \\
\text { depth }\end{array}$ & $\begin{array}{c}\text { Cutting } \\
\text { angle }\end{array}$ & $\begin{array}{c}\text { Holes } \\
\text { number }\end{array}$ & Composite & $\begin{array}{c}\text { Number of filled Partial } \\
\text { end holes }\end{array}$ & fixity & Cost \\
\hline Example 1 & $152 \times 89 \times 16$ & $6.06 \mathrm{~cm}$ & $60^{\circ}$ & 26 & $\sqrt{ }$ & 1 & 0.22 & $\mathbf{6 1 . 6} \$$ \\
Example 2 & $457 \times 152 \times 52$ & $14.3 \mathrm{~cm}$ & $64^{\circ}$ & 20 & $\sqrt{ }$ & 4 & 0.65 & $\mathbf{4 3 1 . 4 \$}$ \\
\hline
\end{tabular}



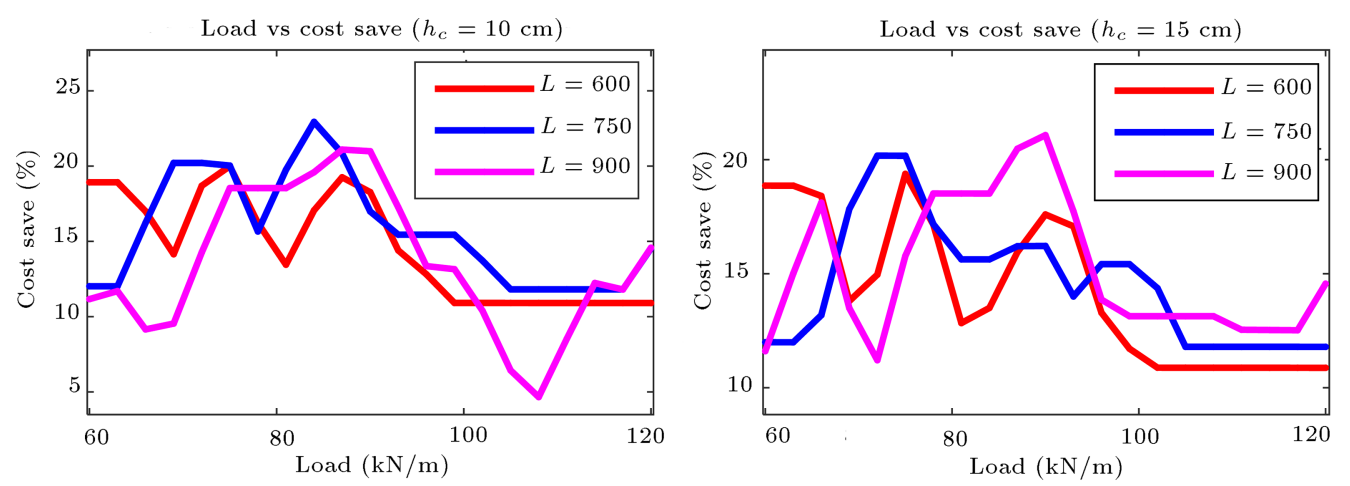

Figure 8. Cost saving percent of using partially fixed connections versus the intensity of distributed load with $10 \mathrm{~cm}$ and $15 \mathrm{~cm}$ concrete thicknesses in Example 3.
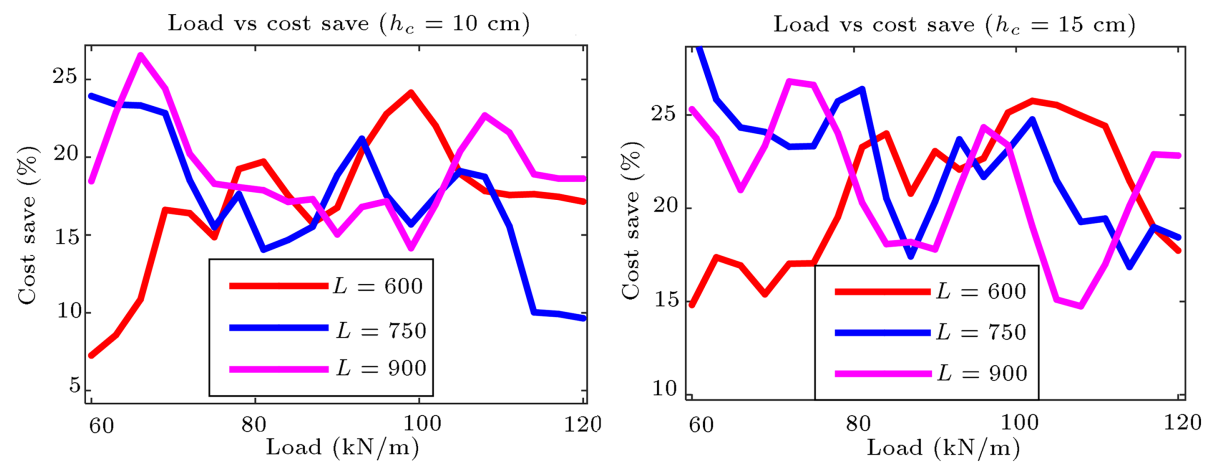

Figure 9. Cost saving percent of using non-commercial cutting shape versus the intensity of distributed load with $10 \mathrm{~cm}$ and $15 \mathrm{~cm}$ concrete thicknesses in Example 3.

condition. Relative difference between the costs of two conditions is considered as the amount of cost saving. Algorithm parameters are similar to those in the previous case.

Figure 8 shows that reduction in optimum cost can be changed from 5 to 25 percent.

\subsubsection{Cost saving of using non-commercial cutting shape}

Difference between the costs of commercial shape and non-commercial shape of the castellated beam is considered as the cost saving of using non-commercial shape of the castellated beam. All variables in noncommercial shape of castellated beam are considered. Number of filled holes is limited to 2. Only ECBO algorithm is used and maximum numbers of iterations and population size are considered 100 and 80 .

Figure 9 shows that the percentage of cost saving can be changed from 6 to 30 .

\section{Discussion and conclusions}

In this paper, the PSO, CBO, and ECBO algorithms were utilized to optimize the process of finding the best property of semi-rigid jointed composite castellated beam.

Comparison of the observations is as follows:
1. Semi-rigid joint composite castellated beam can be viewed as the best choice in the first three examples, and it can decrease the cost by $21 \%$ to $35 \%$;

2. Effect of partial fixity cost saving is estimated 5 to 25 percent;

3. In many problems, horizontal shear at the end of beam controls the optimization problem. Filling the end holes can improve these constraints and it works better in some problems with distributed load. Also, filling the end holes, as far as the first non-filled holes are placed in positive moment length of the beam, can adequately control the horizontal shear and radial moment;

4. The ECBO algorithm seems to result in better design in a higher number of iterations. This efficiency is more sensible when the problem has wide variable bounds and it is more complex;

5. Use of commercial cutting shape for composite castellated beam can increase the cost by 6 to 30 percent.

\section{Acknowledgement}

The first author is grateful to Iran National Science Foundation for the support. 


\section{References}

1. Redwood, R. and Cho, S.H. "Design of steel and composite beams with web openings", J. Construct Steel Res., 25(1), pp. 23-41 (1993).

2. Jackson, R., Vibration and Flexural Strength Characteristics of Composite Castellated Beams, Virginia Polytechnic Institute and State University, USA (2012).

3. Wang, Y. and Li, T. "Flexural bearing capacity research of composite beams with edge constraint component", Adv Mater. Res., 639-640, pp. 807-811 (2013).

4. Ellakany, A.M. and Tablia, H.A. "A numerical model for static and free vibration analysis of elastic composite beams with end shear restraint", Meccan., 45(4), pp. $463-474$ (2010).

5. Morton, S. and Webber, J. "Optimal design of a composite I-beam", Compos. Struct., 28(2), pp. 149168 (1994).

6. Senouci, A.B. and Al-Ansari, M.S. "Cost optimization of composite beams using genetic algorithms", Adv. Eng. Softw., 40(11), pp. 1112-1118 (2009).

7. Sorkhabi, R.V., Naseri, A. and Naseri, M. "Optimization of the castellated beams by particle swarm algorithms method", APCBEE Procedia, 9, pp. 381387 (2014).

8. Kaveh, A. and Shokohi, F. "A hybrid optimization algorithm for the optimal design of laterally-supported castellated beams", Scientia Iranica, 2(23), pp. 508519 (2016).

9. Kaveh, A. and Shokohi, F. "Cost optimization of castellated beams using charged system search algorithm", Iranian J. Sci. Technol., Trans. Civil Eng., 38(C1), pp. 235-249 (2014).

10. Kaveh, A. and Shokohi, F. "Cost optimization of end-filled castellated beams using meta-heuristic algorithms", Int. J. Optim. Civil Eng., 5(3), pp. 333-354 (2015).

11. De Oliveira, T.J.L. and De Miranda Batista, E. "Modelling beam-to-girder semi-rigid composite connection with angles including the effects of concrete tension stiffness", Eng. Struct., 31(8), pp. 1865-1879 (2009).

12. Fu, F., Lam, D. and Ye, J. "Parametric study of semirigid composite connections with $3-\mathrm{D}$ finite element approach", Eng. Struct., 29(6), pp. 888-898 (2007).

13. Gil, B., Goñi, R. and Bayo, E. "Experimental and numerical validation of a new design for threedimensional semi-rigid composite joints", Eng. Struct., 48, pp. 55-69 (2013).

14. Rex, C.O. and Easterling, W.S. "Partially restrained composite beam-girder connections", J. Construct. Steel Res., 58(5), pp. 1033-1060 (2002).

15. Simoes, L. "Optimization of frames with semi-rigid connections", Comput. Struct., 60(4), pp. 531-539 (1996).
16. Kameshki, E. and Saka, M. "Optimum design of nonlinear steel frames with semi-rigid connections using a genetic algorithm", Comput. Struct., 79(17), pp. 15931604 (2001).

17. Ramires, F.B., de Andrade, S.A.L. and de Lima, L.R.O. "Genetic algorithm optimization of composite and steel endplate semi-rigid joints", Eng. Struct., 45, pp. 177-191 (2012).

18. Ali, N.B.H., Sellami, M., Cutting-Decelle, A-F. and Mangin, J.C "Multi-stage production cost optimization of semi-rigid steel frames using genetic algorithms", Eng. Struct., 31(11), pp. 2766-2778 (2009).

19. Committee, A., Specification for Structural Steel Buildings (ANSI/AISC 360-10), American Institute of Steel Construction, Chicago-Illinois, USA (2010).

20. Kerdal, D. and Nethercot, D. "Failure modes for castellated beams", J. Construct. Steel Res., 4(4), pp. 295-315 (1984).

21. Roll, F., Effects of Differential Shrinkage and Creep on a Composite Steel-Concrete Structure, ACI Special Publication, 1971. 27 (2010).

22. Silva, L.S., Simões, R. and Gervásio, H. "Design of steel structures: Eeurocode 3: design of steel structures", Part 1-1: General Rules and Rules for Buildings, John Wiley \& Sons (2012).

23. Murray, T.M., Allen, D.E. and Ungar, E.E., Floor Vibrations Due to Human Activity, American Institute of Steel Construction (2003).

24. Naeim, F., Design Practice to Prevent Floor Vibrations, Steel Committee of California, USA (1991).

25. Golberg, D.E., Genetic Algorithms in Search, Optimization, and Machine Learning, Addison Wesley (1989).

26. Eberhart, R.C. and Kennedy, J. "A new optimizer using particle swarm theory", in Proc. Sixth Int. Symp. Micro Mach. Human Sci., New York, USA (1995).

27. Kaveh, A. and Mahdavi, V.R. "Colliding bodies optimization: A novel meta-heuristic method", Comput. Struct., 139, pp. 18-27 (2014).

28. Kaveh, A. and Ilchi Ghazaan, M. "Enhanced colliding bodies optimization for design problems with continuous and discrete variables", Adv. Eng. Softw., 77, pp. 66-75 (2014).

29. ASCE, Minimum Design Loads for Buildings and Other Structures, American Society of Civil Engineers, Reston, Virginia, USA (2006).

\section{Biographies}

Ali Kaveh was born in 1948 in Tabriz, Iran. After graduation from the Department of Civil Engineering at the University of Tabriz in 1969, he continued his studies on Structures at Imperial College of Science and Technology at London University, and received his MS and PhD degrees in 1970 and 1974, respectively. 
He then joined the Iran University of Science and Technology in Tehran, where he is presently Professor of Structural Engineering. Professor Kaveh is the author of 525 papers published in international journals and 150 papers presented at international conferences. He has authored 23 books in Farsi and 7 books in English published by Wiley, the American Mechanical Society, Research Studies Press, and Springer.
Mohammad Hossein Ghafari was born in 1989 in Tehran. He obtained his BS degree in Civil Engineering from University of Tehran, Iran, In 2012 and his MS degree in Earthquake Engineering from the same university in 2014. At present, he is a PhD student at Iran University of Science and Technology Tehran, Iran, and he works on optimum design of composite floors and steel moments frame via the meta-heuristic methods. 